\title{
Effect of Salinity and PH on the Industrial Effluent Treatment by Activated Carbon: Modeling of the Kinetic Adsorption and Equilibrium Isotherms
}

\author{
E. F. Mohamed \\ Air Pollution Department, Environmental Research Division \\ National Research Centre, Giza, Egypt \\ G. Awad \\ Chemistry of Natural and Microbial Products Department \\ Pharmaceutical and Drug Industries Research Division National Research Centre \\ Giza, Egypt \\ C. Andriantsiferana \\ Laboratory of Chemical Engineering, University of Toulouse \\ ENSIACET, Toulouse, Cedex, France \\ H. Delmas \\ Laboratory of Chemical Engineering, University of Toulouse \\ ENSIACET, Toulouse, Cedex, France
}

Received: December 23, 2018 Accepted: January 9, 2019 Published: January 24, 2019

doi:10.5296/emsd.v8i1.14258 URL: https://doi.org/10.5296/emsd.v8i1.14258

\begin{abstract}
In recent years, interest has been focused on the removal of phenols from contaminated by using a variety of purification techniques. Adsorption of bio-industrial effluent on commercial activated carbon S23 was investigated at ambient conditions. In this wok, phenol and p-hydroxyl benzoic acid (PHBA) was studied as an example of the organic compounds
\end{abstract}


present in the industrial effluent. The effect of temperature, $\mathrm{pH}$, and the presence of inorganic salt $\mathrm{NaCl}$ on the pollutants adsorption were studied to give further comprehension of the optimal conditions of the organic compounds adsorption onto activated carbon. It was noted that the increase in temperature resulted in a decrease in phenols adsorption capacity by S23. Lower phenol adsorption was also observed at the solution $\mathrm{pH} 2$ and 10, whereas, favourable adsorption was reached at neutral solution $\mathrm{pH}$, and the coexisting inorganic salt $\mathrm{NaCl}$ exerts slightly positive effect on the adsorption process. The isotherms obtained at $\mathrm{pH} 2.2$ and 3.5 (non-buffered solution) are very similar and showed a higher adsorption capacity compared with that obtained at $\mathrm{pH} 7$ and 10 for PHBA which is more adsorbable than phenol. The kinetic of the adsorption processes can be better represented by the pseudo-second order. The results showed also that the total organic carbon (TOC) of the industrial effluent reduced for about $20 \%$. Freundlich, Langmuir and Jovanovic adsorption models were used for mathematical description of adsorption equilibrium of phenols. The results showed that the experimental data fitted very well to the Freundlich and Jovanovic models.

Keywords: Phenol, PHBA, Industrial effluent, Adsorption isotherms, Activated carbon, Temperature, $\mathrm{pH}$, Inorganic Salt, Kinetic

\section{Introduction}

Environmental pollution is an emerging threat and great concern in today's context pertaining to its effect on the ecosystem. Industrial effluents often contain various toxic metals, harmful dissolved gases, and several phenolic waste and inorganic compounds (Joshi and Sahu, 2014). The major sources of phenolic waste are petroleum refineries, petrochemical, steel mills, coke oven plants, coal gas, synthetic resins, pharmaceuticals etc. (Bazrafshan et al., 2016). In general, phenolic compounds emit an unpleasant odor and flavor in concentrations as low as $5 \mathrm{~g} / \mathrm{l}$ and are poisonous to aquatic life, plants and human as a product of the bio-concentration (Kamble et al., 2008; Navarro et al., 2008). Ministry of Environment and Forests (MOEF), Government of India and EPA, has set a maximum concentration level of $1.0 \mathrm{mg} \mathrm{l}^{-1}$ of phenol in the industrial effluents for safe discharge into surface waters, the WHO recommends the permissible phenolic concentration of $0.001 \mathrm{mg} \mathrm{l}^{-1}$ in potable waters (Ullhyan and Ghosh 2014). A great variety of adsorbents (natural or synthetic) have been used for the removal of organic substances from industrial air effluents and aqueous solutions. Activated carbons are considered as the most effective organics adsorbents with high surface areas (Andriantsiferana et al., 2015; Mohamed et al., 2015; Mohamed et al., 2016a, 2016b). The adsorption capacity of activated carbon for the liquid adsorption of phenolic compounds depends on the solution conditions such as temperature, $\mathrm{pH}$, ionic strength; and the adsorbate concentration (Magdy et al., 2018). The goal of the present work was firstly to study the adsorption efficiency of S23 commercial activated carbon in the treatment of bio-industrial effluent, and secondly to increase our understanding of adsorption mechanism of the phenols onto activated carbon. To do this, the influence of contact time, temperature, $\mathrm{pH}$, and presence of $\mathrm{NaCl}$ on the adsorption equilibrium of phenol and PHBA was investigated. Kinetic models were used to identify the possible mechanisms of such adsorption process. The Freundlich, Langmuir and Jovanovic models were used to analyze the adsorption equilibrium. 


\section{Experimental}

\subsection{Reagents}

The original industrial effluent wastewater was from the station treatment of SARP INDUSTRIES (Table 1). Two phenolic compounds with different functional groups were studied. These compounds were phenol (-OH) and p-hydroxyl benzoic acid, PHBA (-COOH) (Aldrich Chemical Co. Inc., Milwaukee, WI). All other chemicals used were analytical grade reagents. Commercial activated carbons S23 are obtained from coconut shell (PICA).

Table 1. Characterization of the studied industrial effluent

\begin{tabular}{|c|c|c|c|c|c|c|c|c|c|c|c|c|c|c|}
\hline \multicolumn{2}{|c|}{ General parameter } & \multicolumn{4}{|c|}{ Organic matters } & \multicolumn{3}{|c|}{ Cations } & \multicolumn{3}{|c|}{ Anions } & \multicolumn{3}{|c|}{ Metals } \\
\hline pH & $\begin{array}{c}\text { Conductivity } \\
\left(\mathrm{ms} . \mathrm{cm}^{-1}\right)\end{array}$ & $\begin{array}{c}\text { MES } \\
\left(105^{\circ} \mathrm{C}\right) \\
\left(\mathrm{mg} \cdot \mathrm{L}^{-1}\right) \\
\end{array}$ & $\begin{array}{l}\text { DCO } \\
\left(\mathrm{mg}\left(\mathrm{O}_{2}\right) \cdot \mathrm{L}^{-1}\right)\end{array}$ & $\begin{array}{l}\text { COT } \\
\left(\operatorname{mg}(\mathrm{C}) \cdot \mathrm{L}^{-1}\right)\end{array}$ & $\begin{array}{c}\text { CIT } \\
\text { (mg } \\
\left.\text { (C). } \mathrm{L}^{-1}\right) \\
\end{array}$ & $\begin{array}{l}\mathrm{Na}^{+} \\
\left(\mathrm{g} . \mathrm{L}^{-1}\right)\end{array}$ & $\begin{array}{c}\mathbf{K}^{+} \\
\left(\mathrm{g} . \mathrm{L}^{-1}\right)\end{array}$ & $\begin{array}{l}\mathrm{Ca}^{2^{2+}} \\
\left(\mathrm{g} \cdot \mathrm{L}^{-1}\right)\end{array}$ & $\begin{array}{c}\mathrm{Cl}^{-} \\
\left(\mathrm{g} . \mathrm{L}^{-1}\right)\end{array}$ & $\begin{array}{l}\mathrm{NO}_{3}^{-} \\
\left(\mathrm{g} . \mathrm{L}^{-1}\right)\end{array}$ & $\begin{array}{l}\mathbf{S O}_{4}{ }^{2-} \\
\left(\mathrm{g} . \mathrm{L}^{-1}\right)\end{array}$ & $\begin{array}{c}\mathbf{F e} \\
\left(\mathrm{mg} \cdot \mathrm{L}^{-1}\right)\end{array}$ & $\begin{array}{c}\mathbf{M n} \\
\left(\mathrm{mg} \cdot \mathrm{L}^{-1}\right)\end{array}$ & $\begin{array}{c}\mathbf{Z n} \\
\left(\mathrm{mg} \cdot \mathrm{L}^{-1}\right)\end{array}$ \\
\hline 6.9 & 11.7 & 117 & $500-700$ & $100-110$ & 27 & 2.4 & 0.8 & 0.3 & 4.4 & 0.35 & 0.6 & 1.2 & 1.1 & 0.6 \\
\hline
\end{tabular}

\subsection{Activated Carbon Characterization}

\subsubsection{Surface Area and Porosity}

Surface area was determined using nitrogen as the sorbate at $77 \mathrm{~K}$ in a static volumetric apparatus (Micromeritics ASAP 2010 sorptometer). Specific total surface areas were calculated using BET equation.

\subsubsection{Boehm Titration}

Carbon sample $(1 \mathrm{~g})$ was placed in $50 \mathrm{ml}$ of $0.05 \mathrm{~N}$ of the following solutions: sodium hydroxide, sodium carbonate, sodium bicarbonate, and hydrochloric acid. The excess base or acid was titrated with $\mathrm{HCl}(0.1 \mathrm{~N})$ or $\mathrm{NaOH}(0.1 \mathrm{~N})$, respectively. The number of acidic sites was determined under the assumption that $\mathrm{NaOH}$ neutralizes carboxylic, lactonic, and phenolic groups; and $\mathrm{Na}_{2} \mathrm{CO}_{3}$ neutralizes carboxylic and lactonic groups; and $\mathrm{NaHCO}_{3}$ neutralizes only carboxylic groups. The number of basic sites was calculated from the amount of hydrochloric acid that reacted with the carbon.

\subsection{3 $\mathrm{pH}$ at the Point of Zero Charge and Metal Contents}

The $\mathrm{pH}$ at the point of zero charge ( $\mathrm{pHpzc}$ ) of sample was determined by mass titration method (Canizares et al., 2006). To determine the right concentration of carbon, a titration curve was first obtained. Different carbon concentration slurries in deionised water were prepared, then shaken for $24 \mathrm{~h}$ and the final $\mathrm{pH}$ of the slurry was measured with the $\mathrm{pH}$ meter. For values greater than $5 \% \mathrm{wt}$, the $\mathrm{pH}$ value obtained was constant. Therefore, for all samples, this amount of carbon was used and the resulting $\mathrm{pH}$ taken as the pHpzc. The values of the metals composition and the elemental analyses of commercial AC S23 samples were obtained from the industrial Supplier (PICA, Veolia group).

\subsection{Total Organic Carbon}

The Total Organic Carbon (TOC) is a parameter for measuring the organic matter present in wastewater. This test is performed by injecting a known quantity of sample into a high 


\section{Macrothink}

temperature furnace in a chemically oxidizing environment. Thus the organic carbon is oxidised to carbon dioxide in the presence of a platinum catalyst. The TOC was measured by TC Multi Analyser 2100 N/C equipment from Analytic Jena with a non-diffractive IR detector. Sample acidification and aeration prior to analysis eliminate errors due to the presence of inorganic carbon.

\subsection{Adsorption Experiments}

\subsubsection{Kinetic Study}

In order to determine the time required for reaching the adsorption equilibrium, phenol and PHBA solutions were put in contact with the activated carbon S23 for different times, at a constant temperature of $25 \mathrm{C}^{\circ}$. For that purpose, a number of samples were prepared by mixing $0.5 \mathrm{~g}$ of $\mathrm{AC}$ with $2.35 \mathrm{~g} \mathrm{l}^{-1}$ of a solution of phenol and others of PHBA $\left(3.38 \mathrm{~g} \mathrm{l}^{-1}\right)$, shaken, filtered and then analysed by an HPLC apparatus. The amount of phenol adsorbed on the activated carbon samples at different contact times was calculated by the difference between the initial and the final phenol concentrations. The kinetic data obtained from batch studies have been analyzed by using pseudo-first-order and pseudo-second-order models. The first order equation of Lagergren is generally expressed as follows (Srihari and Das, 2008):

$$
d q / d t=K 1(\mathrm{qe}-\mathrm{q})
$$

Where $q_{e}$ and $\mathrm{q}$ are the amounts of pollutant adsorbed $\left(\mathrm{mg} \mathrm{g}^{-1}\right)$ at equilibrium and at time $\mathrm{t}$ (min), respectively, and $K_{1}$ is the rate constant of pseudo-first-order sorption $\left(\min ^{-1}\right)$. The integrated form of Eq. (1) becomes Eq. (2)

$$
\ln (q e-q)=\ln q e-K 1 t
$$

The pseudo-second-order kinetic rate equation is expressed by Robati, 2013, as shown in Eq. (3):

$$
\frac{\mathrm{dq}}{\mathrm{dt}}=K_{2}(q e-q)^{2}
$$

Where $\mathrm{k}_{2}$ is the rate constant of pseudo-second-order sorption $\left(\mathrm{g} \mathrm{mg}^{-1} \mathrm{~min}^{-1}\right)$. The integrated form of Eq. (3) becomes Eq. (4)

$$
\frac{t}{q}=\frac{1}{K_{2} q e^{2}}+\frac{1}{q e} t
$$




\subsubsection{Adsorption Equilibrium}

Phenols solution of different initial concentrations (ranging from 188.22 to $5176.05 \mathrm{mg}^{-1}$ ) were shaken with $0.5 \mathrm{~g}$ of AC S23 in a $250 \mathrm{ml}$ bottle using the batch bottle-point technique at a constant temperature $25 \mathrm{C}^{\circ}$ for three days. After equilibrium, samples were filtered, analysed and the amount of adsorbed phenol and PHBA was then deduced.

\subsubsection{Modeling of the Adsorption Isotherms}

Many models have been used to describe the equilibrium relationship between solute and activated carbon in both single and multi-component systems. The mono-component isotherms were evaluated according to the two parameter models (Langmuir, Freundlich and Jovanovic). The adsorption models constants, the values of which express the surface properties and affinity of the adsorbent, can be used to compare the adsorptive capacity of adsorbents for different compounds.

Langmuir equation is the most isotherm equation used for modelling of the monolayer adsorption data (Altaher et al., 2015), is given by Eq. (5).

$$
q_{e}=\frac{q_{\max } K_{L} C_{E}}{1+K_{L} C_{e}}
$$

Where $q_{\mathrm{e}}$ is the amount of adsorbate taken up on adsorbent at equilibrium ( $\left.\mathrm{mg} \mathrm{g}^{-1}\right), C_{\mathrm{e}}$ the equilibrium concentration of the adsorbate in aqueous solution $\left(\mathrm{mg} \mathrm{l}^{-1}\right), q_{\max }$ and $K_{L}$ are the Langmuir constants, representing the maximum adsorption capacity for the solid phase loading and the energy constant related to the heat of adsorption, respectively.

Freundlich model is used to describe the heterogeneous surface. It is given by Eq. (6).

$$
q_{e}=K_{f} C_{e}^{\frac{1}{n}}
$$

Where $K_{\mathrm{F}}$ is the Freundlich constant for a heterogeneous adsorbent, and $n$ is related to the magnitude of the adsorption driving force and to the adsorbent site energy distribution. The value of $n$ indicates favourable adsorption when $1<n<10$ (Altaher et al., 2015).

Jovanovic model is a simple isotherm model for homogeneous surfaces without lateral interactions; this model is suitable for monolayer adsorption and is given by Eq. (7) (Jaroniec 1976).

$$
q=q_{\max }\left(1-e^{-k c}\right)
$$

Where $q$ is the amount of adsorbate taken up on adsorbent at equilibrium $\left(\mathrm{mg} \mathrm{g}^{-1}\right), C_{\mathrm{e}}$ the equilibrium concentration of the adsorbate in aqueous solution $\left(\mathrm{mg} \mathrm{l}^{-1}\right), q_{\max }$ and $K$ are the constants. 


\subsubsection{Nonlinear Least Squares Analysis}

Regression of the experimental data to the adsorption isotherm models were performed using a corrected Gauss-Newton algorithm. The procedure calculates the values of the isotherm parameters which minimize the residual sum of squares (RSS):

$$
\text { RSS }=\sum_{i=1}^{n}\left(q_{\exp , i}-q_{t, i}\right)^{2}
$$

Where $q_{\mathrm{ex}, \mathrm{i}}$ are the elements of the vector $\mathrm{q}_{\mathrm{ex}}$ containing the given experimental adsorbed phase concentrations, $\mathrm{n}$ is data points and $q_{\mathrm{t}, \mathrm{i}}$ are the corresponding theoretical values calculated by model being studied. The selection of the most adequate model was performed using the Fisher's test. The model selected was the one which exhibited the highest value $\mathrm{F}_{\text {calc }}$ of Fisher parameter, Eq. (9) and having the lowest value of absolute relative errors (AARE), Eq. (10).

$$
\begin{aligned}
& F_{\text {cale }}=\frac{(\mathrm{n}-1) \sum_{\mathrm{i}=1}^{\mathrm{n}}\left(q_{\exp , i} \mathrm{i}-q_{\exp }\right) 2}{(\mathrm{n}-1) \sum_{\mathrm{i}=1}^{\mathrm{n}}\left(q_{\exp , i} \mathrm{i}-q_{\mathrm{t}, \mathrm{i}}\right)^{2}} \\
& A A R E=\frac{100}{n} \cdot \sum_{i=1}^{n}\left(\frac{\left|q_{\exp i}-q_{t, i}\right|}{q_{\exp , i}}\right)
\end{aligned}
$$

Where $q_{\mathrm{ex}}$ is the mean value of the vector $q_{\mathrm{ex}}$ and $I$ is the number of adjusted parameters of the model.

\subsection{Effect of Solution Condition}

\subsubsection{Effect of Temperature}

The effect of temperature in the phenols adsorption experiments were investigated at temperature of 25 and $50{ }^{\circ} \mathrm{C}$. It is important to study the thermodynamic parameters such as the change in the apparent enthalpy, $\Delta \boldsymbol{H}(\mathrm{KJ} / \mathrm{mol})$ and the Gibbs free energy, $\Delta \boldsymbol{G}(\mathrm{KJ} / \mathrm{mol})$ and the entropy change, $\Delta S(\mathrm{KJ} / \mathrm{mol} \mathrm{K})$, of adsorption by using the Langmuir constant $\mathrm{K}_{\mathrm{L}}$ using the following thermodynamic equations (Brucher and Bergstram 1997):

$$
\begin{gathered}
\ln K_{L}=\frac{\Delta S}{R}-\frac{\Delta \mathrm{H}}{R T} \\
\frac{\Delta \mathrm{G}}{R T}=\frac{\Delta \mathrm{H}}{R T}-\frac{\Delta S}{R}
\end{gathered}
$$

Where $K_{L}$ denotes the equilibrium constant, $R$ is universal gas constant and $T$ is the absolute temperature in Kelvin. The standards enthalpy $\Delta \boldsymbol{H}$ and entropy changes $\Delta \boldsymbol{S}$ are respectively determined from the slope and intercept of the plot $\ln K_{L}$ against $1 / T$. 


\section{I Macrothink}

\subsubsection{Effect of Solution $\mathrm{pH}$}

In order to study the effect of the $\mathrm{pH}$ on the adsorption of phenol onto activated carbon, different initial solution $\mathrm{pH}$ values $(2.2,7$ and 10) maintained by means of ionic buffer solutions (phosphates buffers) were used. The ionic fraction (ions $\varphi$ ) can be evaluated from equation (13):

$$
\emptyset_{\text {ions }}=\frac{1}{1+10^{p k a-p H}}
$$

\subsubsection{Addition of $\mathrm{NaCl}$}

The effect of salinity on the phenols removal by activated carbon S23 was studied by adding different amount of $\mathrm{NaCl}$ salt to the solutions.

\section{Results and Discussion}

\subsection{Activated Carbon Characterization}

Surface area of the activated carbon was found to be $1230 \mathrm{~m}^{2} \mathrm{~g}^{-1}$ (Table 2). The results of Boehm titration was represented in Table 3. The surface function groups was mainly basic groups and the $\mathrm{pH}$ was found to be 9.8. The results of the metals content and the elemental analyses of S23 was summarised in Table 4.

Table 2. Characterization of Activated carbon S23

\begin{tabular}{|l|l|lr|lr|l|l|}
\hline $\begin{array}{l}\text { Activated } \\
\text { Carbon }\end{array}$ & $\begin{array}{l}\text { BET Surface } \\
/ \mathrm{m}^{2} \mathrm{~g}^{-1}\end{array}$ & $\begin{array}{l}\text { Mesoporous vol. } \\
/ \mathrm{cm}^{3} \mathrm{~g}^{-1}\end{array}$ & $\begin{array}{l}\text { Microporous vol. } \\
/ \mathrm{cm}^{3} \mathrm{~g}^{-1}\end{array}$ & $\begin{array}{l}\text { Pore } \\
\varnothing / \AA\end{array}$ & $\begin{array}{l}\text { Apparent density } \\
/ \mathrm{kg} \mathrm{m}^{-3}\end{array}$ \\
\hline $\mathrm{S} 23$ & 1230 & 0.04 & 0.49 & 17 & 1013 \\
\hline
\end{tabular}

Table 3. Results of Boehm titration for the activated carbon S23

\begin{tabular}{|c|c|c|c|c|c|c|}
\hline $\begin{array}{c}\text { Activated } \\
\text { Carbon }\end{array}$ & $\begin{array}{c}\text { Carboxylic } \\
\text { group } \\
\left(\mathrm{mM} \mathrm{g} \mathrm{g}^{-1}\right)\end{array}$ & $\begin{array}{c}\text { Lactonic } \\
\text { group } \\
\left(\mathrm{mM} \mathrm{g^{-1 } )}\right.\end{array}$ & $\begin{array}{c}\text { Phenolic } \\
\text { group } \\
\left(\mathrm{mM} \mathrm{g}^{-1}\right)\end{array}$ & $\begin{array}{c}\text { Total acidic } \\
\text { sites } \\
\left(\mathrm{mM} \mathrm{g}^{-1}\right)\end{array}$ & $\begin{array}{c}\text { Total basic } \\
\text { sites } \\
\left(\mathrm{mM} \mathrm{g} \mathrm{g}^{-1}\right)\end{array}$ & $\boldsymbol{p H}_{\text {PZC }}$ \\
\hline $\mathbf{S 2 3}$ & - & 0.1 & 0.05 & 0.2 & 1.00 & 9.8 \\
\hline
\end{tabular}

Table 4. Metal composition and element analysis of AC S23

\begin{tabular}{|l|c|c|c|c|c|c|c|c|c|c|c|}
\hline \multirow{3}{*}{ Activated Carbon } & \multicolumn{4}{|c|}{ Metal-content (by ICP) } & \multicolumn{4}{c|}{ Elemental analyses (in ppm) } \\
\cline { 2 - 12 } & $\mathrm{Zn}$ & $\mathrm{Ni}$ & $\mathrm{CO}$ & $\mathrm{Mn}$ & $\mathrm{Fe}$ & $\mathrm{Cu}$ & $\mathrm{O} \%$ & $\mathrm{C} \%$ & $\mathrm{H} \%$ & $\mathrm{~N} \%$ & $\mathrm{~S} \%$ \\
\hline S23 & 13 & 3 & 0 & 5 & 116 & 74 & 2.34 & 92.28 & 0.58 & 0.30 & - \\
\hline
\end{tabular}

\subsection{Kinetics of Phenol and PHBA Adsorption}

Numerous kinetic models have been proposed to elucidate the mechanism by which pollutants may be adsorbed. The mechanism of adsorption depends on the physical and/or chemical characteristics of the adsorbent as well as on the mass transport process. In order to investigate the mechanism of the phenol and PHBA adsorption, the kinetic data have been 


\section{Macrothink}

analysed by using pseudo first-order and pseudo second -order models. In order to quantify the applicability of each model, the correlation coefficient, $R^{2}$, was calculated. The plots of linearized form of the pseudo first-order and pseudo-second-order kinetic equations for phenol and PHBA are shown in Figure 1. The different parameters of both models are summarized in table 5. The results showed that, the correlation coefficient values, $\mathrm{r}_{2}{ }^{2}$ were found to be higher than $\mathrm{r}_{1}{ }^{2}$ for both phenol and PHBA. In the view of these results, it can be said that the pseudo-second -order kinetic model provided a good correlation for the adsorption of phenol and PHBA $\left(\mathrm{r}_{2}{ }^{2}=0.999\right)$ onto activated carbon S23 in contrast to the pseudo-first-order model $\left(\mathrm{r}_{1}{ }^{2}=0.63\right.$ for phenol and 0.92 for PHBA).
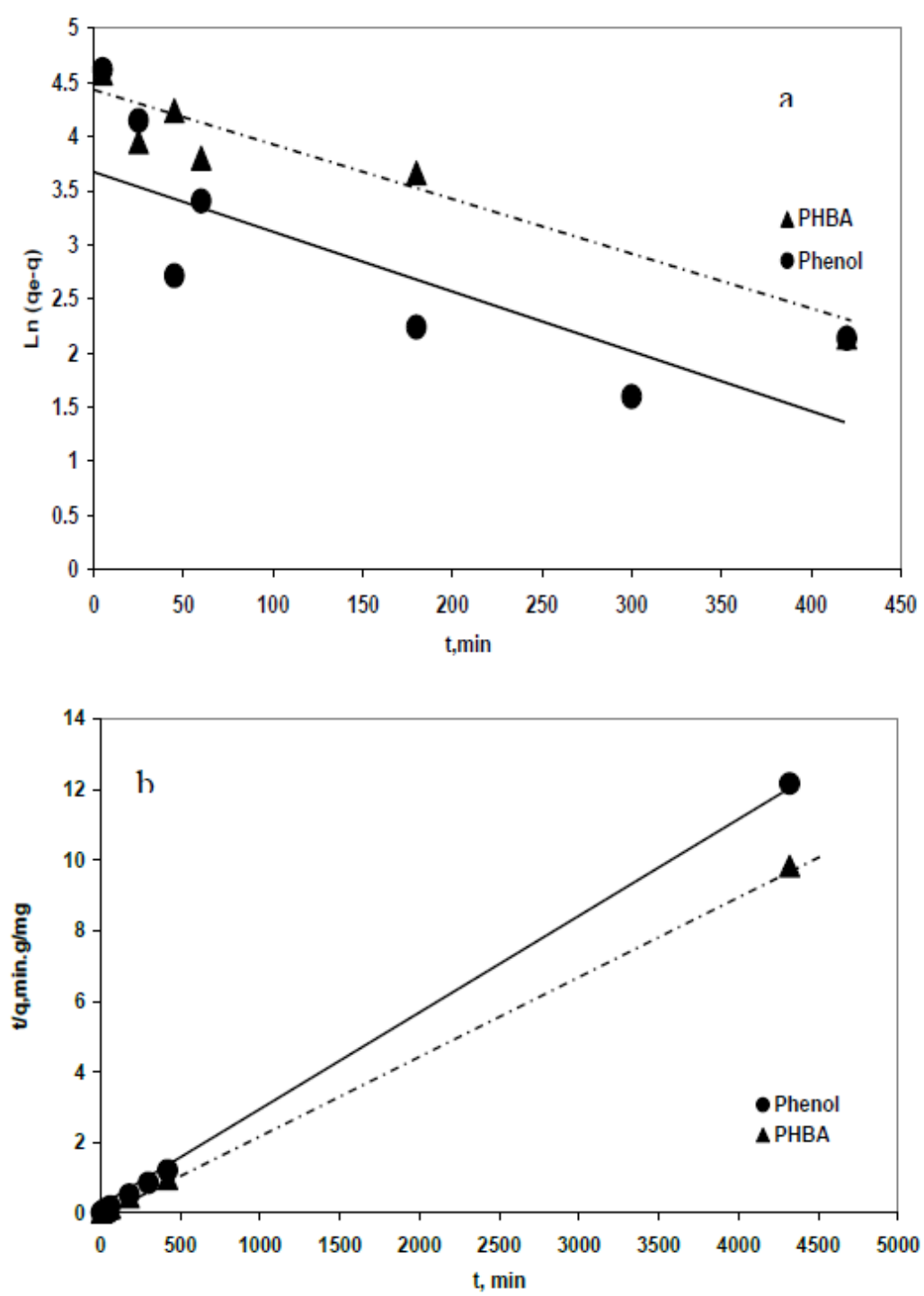

Figure 1. First order (a) and second order (b) kinetics for adsorption of phenol and PHBA onto AC S23 


\section{Macrothink}

Table 5. Pseudo-first order and Pseudo second order kinetic parameters for the adsorption of phenol and PHBA onto activated carbon S23

\begin{tabular}{|l|l|l|l|l|l|l|}
\hline \multirow{2}{*}{ Pollutant } & \multicolumn{3}{|c|}{ Pseudo-first order } & \multicolumn{3}{c|}{ Pseudo-second order } \\
\cline { 2 - 7 } & $\mathrm{q}_{\mathrm{e}}\left(\mathrm{mg}_{\mathrm{g}} \mathrm{g}^{-1}\right)$ & $\mathrm{K}_{1}\left(\mathrm{~min}^{-1}\right)$ & $\mathrm{R}_{1}{ }^{2}$ & $\mathrm{q}_{\mathrm{e}}\left(\mathrm{mg}_{\mathrm{g}} \mathrm{g}^{-1}\right)$ & $\mathrm{K}_{2}\left(\mathrm{~min}^{-1}\right)$ & $\mathrm{R}_{2}{ }^{2}$ \\
\hline Phenol & $1.5646 \mathrm{e}^{-}$ & 0.0056 & 0.6381 & 357 & 0.00056 & 0.9999 \\
\hline PHBA & $4.3782 \mathrm{e}-{ }^{5}$ & 0.0051 & 0.9241 & 434 & $2.9887 \mathrm{e}^{-4}$ & 0.9999 \\
\hline
\end{tabular}

\subsection{Equilibrium Isotherms}

\subsubsection{Adsorption Isotherms of Industrial Effluent}

Figure 2 shows the adsorption isotherms of organic pollutants analysed as COT from the industrial effluent onto the commercial AC S23. It can be observed that the concentration of COT was reached to nearly $20 \%$ after the adsorption. The experimental equilibrium data fitted well to the freundlich model. Fitting parameters and regression coefficients obtained are shown in Table 6.

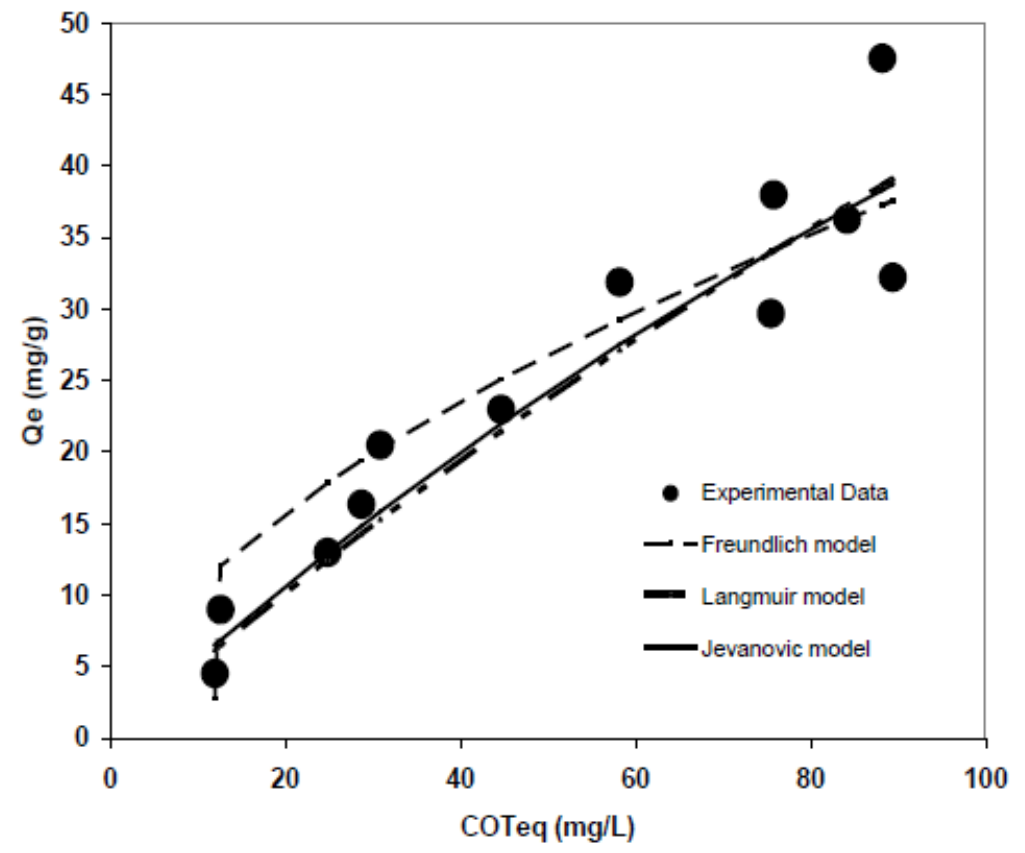

Figure 2. Comparison of different isotherms models for COT of the industrial effluent adsorption onto $\mathrm{S} 23$ at temperature $25 \mathrm{C}^{\circ}$ : Freundlich model fitting 
Table 6. Different parameter values of isotherm adsorption models of phenol, PHBA and TOC after the nonlinear regression analysis

\begin{tabular}{|c|c|c|c|c|c|c|c|c|c|c|c|c|c|c|c|}
\hline \multirow[t]{2}{*}{ Adsorbate } & \multicolumn{5}{|c|}{ Langmuir } & \multicolumn{5}{|l|}{ Freundlich } & \multicolumn{5}{|c|}{ Jovanovic } \\
\hline & $\begin{array}{l}\mathrm{q}_{\max } \\
\left(\mathrm{mg} \cdot \mathrm{g}^{-1}\right)\end{array}$ & $\begin{array}{l}\mathrm{K} \\
\left(\mathrm{L} \cdot \mathrm{mg}^{-1}\right) \\
\end{array}$ & RSS & $F_{\text {calc }}$ & $\begin{array}{l}\text { AARE } \\
(\%) \\
\end{array}$ & $\begin{array}{l}\mathrm{K} \quad\left(\mathrm{mg}^{1-}\right. \\
\left.{ }^{\gamma} \cdot \mathrm{L}^{\gamma} \cdot \mathrm{g}^{-1}\right)\end{array}$ & $\gamma(-)$ & RSS & $F_{\text {calc }}$ & $\begin{array}{l}\text { AARE } \\
(\%)\end{array}$ & $\begin{array}{l}\mathrm{q}_{\max } \\
\left(\mathrm{mg} \cdot \mathrm{g}^{-1}\right)\end{array}$ & $\begin{array}{l}\mathrm{K} \\
\left(\mathrm{L} \cdot \mathrm{mg}^{-1}\right)\end{array}$ & RSS & $F_{\text {calc }}$ & $\begin{array}{l}\text { AARE } \\
(\%)\end{array}$ \\
\hline Phenol & 434 & 0.009 & 14514 & 9.51 & 15.96 & 55.68 & 0.27 & 4433 & 31.13 & 6.17 & 335 & 0.024 & 37738 & 3.66 & 17.00 \\
\hline PHBA & 579 & 0.003 & 3122 & 128.47 & 4.88 & 8.21 & 0.58 & 17402 & 11.21 & 14.04 & 433 & 0.004 & 1191 & 336.66 & 3.40 \\
\hline $\begin{array}{l}\text { TOC } \\
\text { (Industrial } \\
\text { effluent) }\end{array}$ & 218 & 0.002 & 224 & 31.26 & 16.24 & 2.75 & 0.58 & 224 & 31.29 & 11.50 & 91 & 0.006 & 213 & 32.96 & 15.32 \\
\hline
\end{tabular}

\subsubsection{Phenol and PHBA Adsorption Isotherms}

Figure 3 shows the adsorption of phenol and PHBA on the commercial AC S23. The data were analyzed using Langmuir, Javanovic and Freundlich equations. The results of the regression analysis of the different models evaluated are reported in Table 6 . The selection of the most adequate model was performed using the Fisher's test. The adsorption phenol equilibrium data fitted Freundlich equation with $F_{\text {calc }}$ and AARE values of 31 and 6, respectively. However the highest value of $F_{\text {calc }}(336)$ and the lowest value of AARE (3.5) confirm that the adsorption PHBA equilibrium data fitted Jovanovic model. 

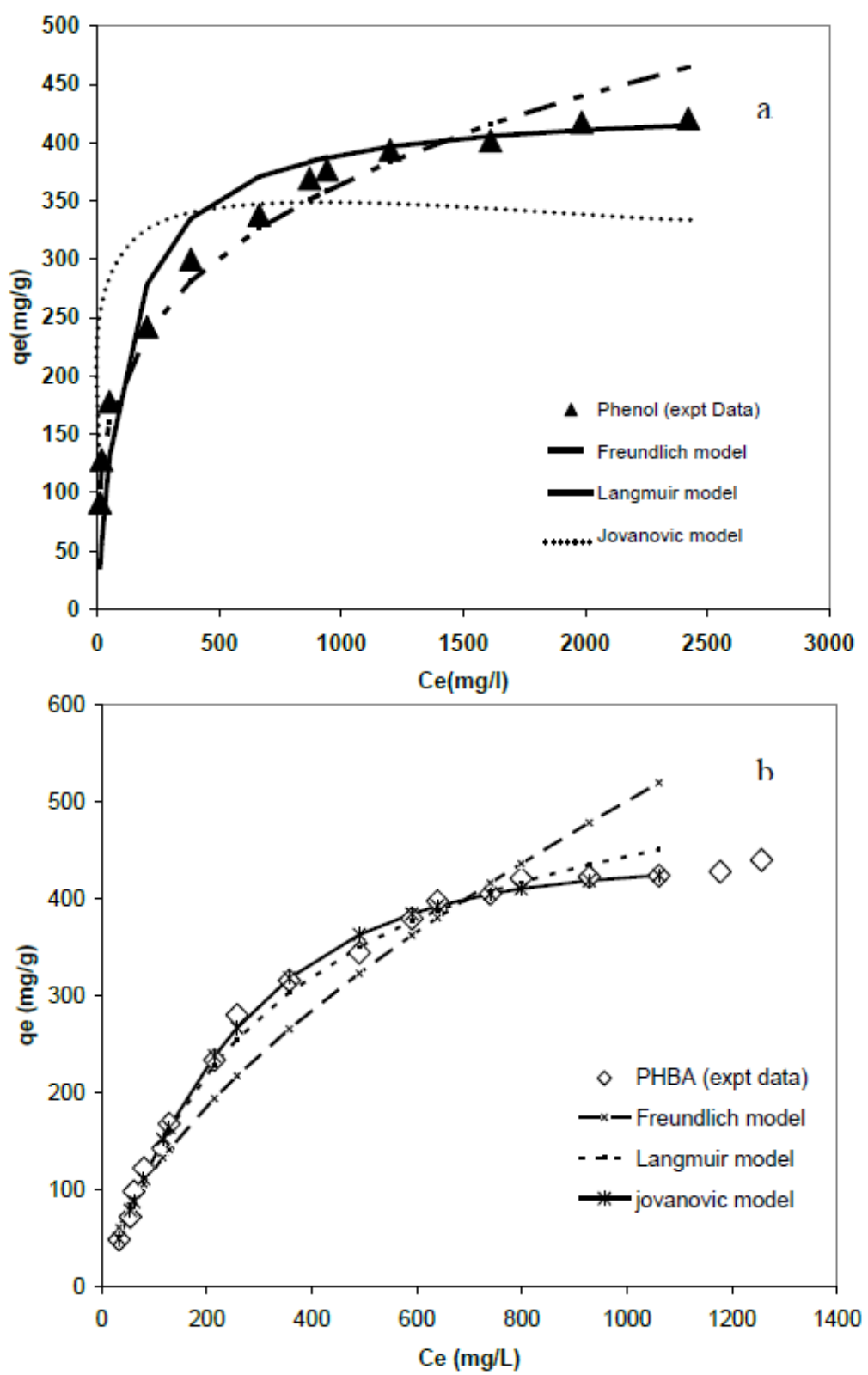

Figure 3. Comparison of different isotherm models for phenol (a) and PHBA (b) adsorptions onto AC S23

\subsection{Temperature Effect}

It is clear from these Figure 4 that the experimental data fitted well with Langmuir model and the equilibrium adsorption of phenol and PHBA decreases with increasing temperature as revealed by the values of $q_{\max }$, for example, by increasing the temperature from $25{ }^{\circ} \mathrm{C}$ to 50 $\mathrm{C}^{\circ}$, the maximum adsorption capacity for phenol decreased from $434 \mathrm{mg} \mathrm{g}^{-1}$ to $319 \mathrm{mg} \mathrm{g}^{-1}$ (Table 7). It is known that AC has strongly heterogeneous surface. The heterogeneity of the AC surface stems from two sources, namely geometrical and chemical. The geometrical heterogeneity (porosity) is the result of differences in the size and shape of pores, as well as pits, vacancies and steps. Chemical heterogeneity is associated with different functional groups at a surface, and with various surface contaminants. Both the chemical and 
geometrical heterogeneities contribute to the unique adsorption properties of activated carbon. The effect of carbon surface chemical composition on the adsorption of phenol decreases with rising temperature and geometrical heterogeneity determines adsorption of phenol at higher temperatures. However, at ambient temperature, the influence of surface functionalities is significant. The mechanism of phenol adsorption is also determined by the so-called "solvent effect". Adsorption of water by ACs together with the change in the energy of phenol-water interactions with the rise in temperature greatly changes the mechanism of phenol adsorption. (Pan et al., 2008). As shown in the table 7, the negative value of $\Delta \boldsymbol{G}$ confirms the feasibility of the process and the spontaneous nature of adsorption. The negative values of $\boldsymbol{\Delta} \boldsymbol{H}$ were, indicating that the adsorption reaction is exothermic. This effect of temperature on the adsorption of phenol is expected for physical adsorption that is exothermic in nature in most cases (Sharma et al., 2016).

Table 7. Thermodynamic parameters for the adsorption of phenols on AC S23

\begin{tabular}{|c|c|c|c|c|c|c|c|c|}
\hline \multirow[t]{2}{*}{ Adsorbate } & \multicolumn{2}{|c|}{$\mathrm{q}_{\max }\left(\mathrm{mg} \cdot \mathrm{g}^{-1}\right)$} & \multicolumn{2}{|c|}{$\mathrm{K}\left(\mathrm{L} \cdot \mathrm{mg}^{-1}\right)$} & \multicolumn{2}{|c|}{$\Delta G\left(\mathrm{KJ} \cdot \mathrm{mol}^{-1}\right)$} & \multirow{2}{*}{$\begin{array}{c}\Delta S \\
\left(\mathrm{KJmol}^{-1} \mathrm{~K}^{-1}\right)\end{array}$} & \multirow{2}{*}{$\begin{array}{c}\Delta H \\
\left(\mathrm{KJmol}^{-1}\right)\end{array}$} \\
\hline & $25^{\circ} \mathrm{C}$ & $50^{\circ} \mathrm{C}$ & $25^{\circ} \mathrm{C}$ & $50^{\circ} \mathrm{C}$ & $25^{\circ} \mathrm{C}$ & $50^{\circ} \mathrm{C}$ & & \\
\hline Phenol & 434 & 319 & 0.008 & 0.048 & -11.79 & 12.22 & -2.59 & -6.60 \\
\hline PHBA & 0.003 & 0.004 & 1.731 & 1.792 & -0.18 & 0.12 & 17.40 & -0.96 \\
\hline
\end{tabular}

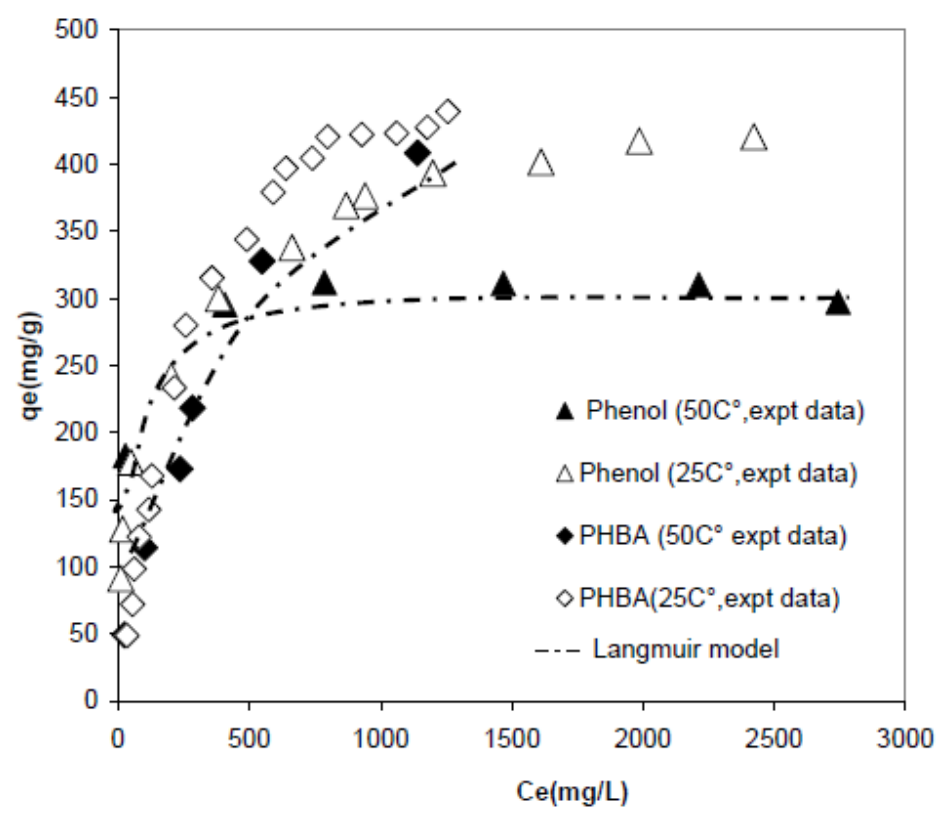

Figure 4. Adsorption isotherms of phenol and PHBA onto AC S23 at temperature 25 $\mathrm{C}^{\circ}$ and $50 \mathrm{C}^{\circ}$ : Langmuir model fitting

\subsection{Effect of Solution $\mathrm{pH}$}

The $\mathrm{pH}$ of the solution is one of the major factors influencing the adsorption capacity of compounds that can be ionized. Acid or alkali species may change the surface chemistry of the adsorbent by reacting with surface groups. At low $\mathrm{pH}$ values, the surface of the activated carbon would be protonated and resulted in a stronger attraction for negatively charge phenolate ions. Phenol, being weakly acidic $(\mathrm{pKa}=10)$, partially ionizes in solution. These 
ions are negatively charged and are directly attracted to the protonated surface of activated carbon by electro-static force. Unionized phenol molecules would also be attracted, possibly,

by physical force. At high $\mathrm{pH}, \mathrm{OH}^{-}$ions would compete with the phenol molecules for

sorption sites. Sorption of excess of $\mathrm{OH}^{-}$ions could convert an initial positively charged surface of activated carbon into a negatively charged surface resulting repulsion of negatively charged phenoxide ions and adsorption decreased (Machida et al., 2016). The effect of $\mathrm{pH}$ on the removal of the phenol and PHBA using AC S23 is presented in Figure 5. As can be seen in this figure, the adsorption amounts of phenol onto activated carbon increased at neutral solution $\mathrm{pH} 7$ and nonbuffered solution, $\mathrm{pH}$ 5.8. At the lower $\mathrm{pH}$, the functional groups on the carbon surface are in the protonated form and high electron density on the solute molecules would lead to higher adsorption. At higher $\mathrm{pH}$, the phenol dissociate, forming phenolate anions, whereas surface functional groups may be either neutral or negatively charged. The electrostatic repulsion between the like charges lowers the adsorption capacities in case of the phenol. This may be due to the dependence of phenol ionization on $\mathrm{pH}$ of the medium. Phenols being weak acid ( $\mathrm{pKa}=9.89$ ) will be adsorbed to a lesser extent at higher $\mathrm{pH}$ values due to the repulsive force prevailing at higher $\mathrm{pH}$. A similar trend has been reported for the adsorption of PHBA on the activated carbons. At $\mathrm{pH}=2.2$ and 3.5, PHBA was found in the protonated form where its $\mathrm{pH}$ is lower than $4.8\left(\mathrm{p}^{\mathrm{ka}}\right)$, so its higher adsorption capacity is not only due to the presence of electron attracting group $-\mathrm{COOH}$ but also it was adsorbed by donor- acceptor mechanism. At $\mathrm{pH}=7$, it is partially ionized, having an electron donating group O- and protons which adsorbed preferentially, so it has very weak adsorption capacity. Finally, at $\mathrm{pH}=10$, higher than $\mathrm{p}^{\mathrm{ka}}$, its adsorption capacity is lower since it is completely ionized. These results are in agreement with those reported by $\mathrm{Gu}$ et al., 2008 and Mohammad et al., 2016. The pKa values of phenol and PHBA at $30{ }^{\circ} \mathrm{C}$ are 9.89 and 4.8, respectively (Hameed and Rahman 2008; Li et al . 2009). When pH of solution goes beyond the pKa of phenols, phenols chiefly exist as negative phenolate ions, while they are molecules below pKa. Therefore, we consider that phenols effectively adsorbed onto adsorbent are molecules not phenolate anions. Thus, the molecular interactions including hydrogen bonding, hydrophobic interaction and Van der Waals forces are the possible factors for the adsorption of phenols. On the other hand, the higher adsorption capacity in non-buffered isotherm can be interpreted in terms of the competitive adsorption of phenol and the phosphates contained in the buffer system. According to that, when buffer solutions are used to know the $\mathrm{pH}$ effects, on the adsorption, the carbon adsorption capacity for the adsorbate is diminished due to the buffer solution uptake.As seen from the results that the equilibrium data for phenol and PHBA at various $\mathrm{pH}$ values were well represented by the Frendluich isotherm model. 

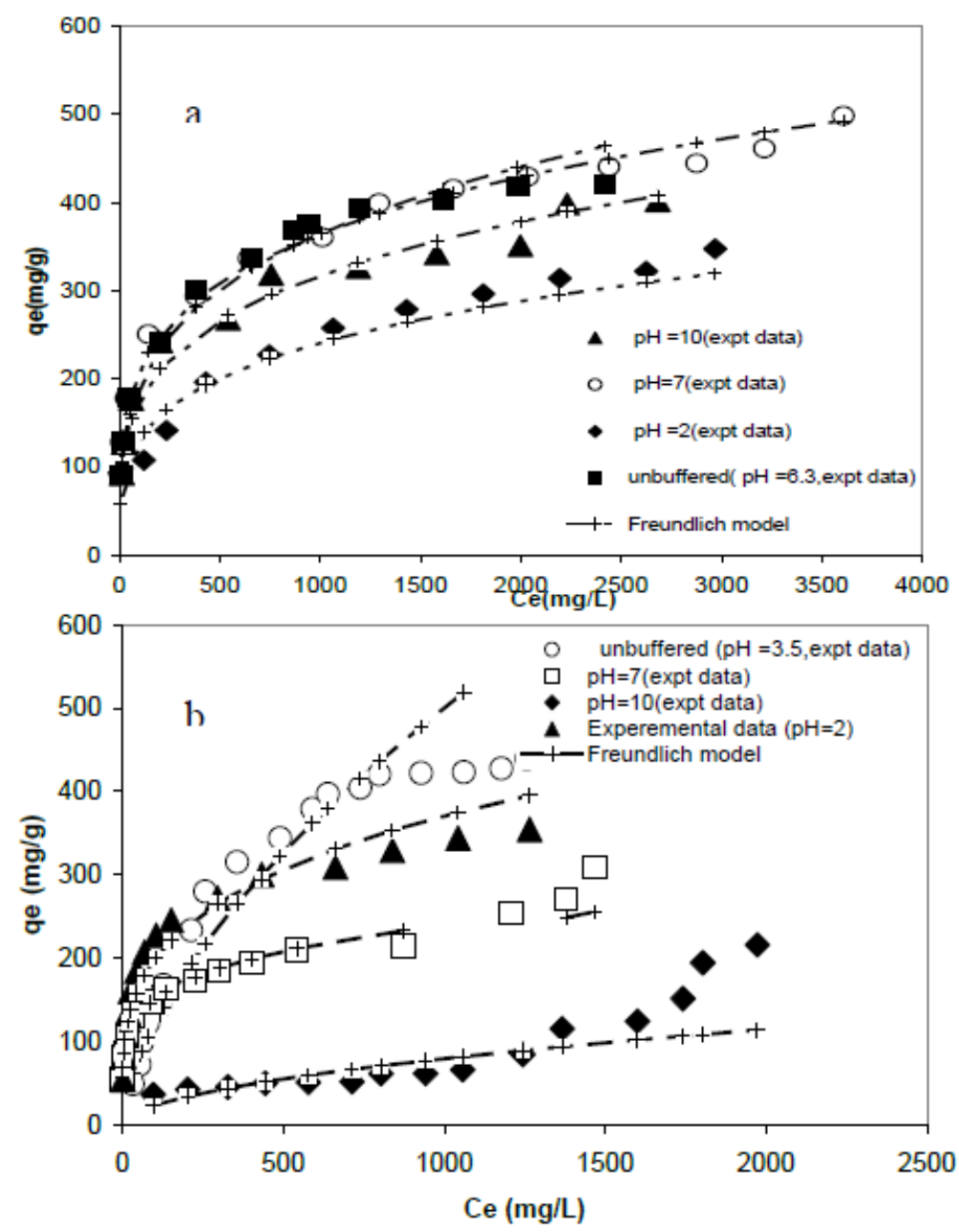

Figure 5. Effect of pH on the adsorption of phenol (a) and PHBA (b) onto AC S23 at temperature $25 \mathrm{C}^{\circ}$ : Freundlich model fitting

\subsection{Effect of $\mathrm{NaCl}$}

Figure 6 and 7 show the adsorption behaviour of phenol and PHBA under different $\mathrm{NaCl}$ concentration. It is seen also that an increase in the salt concentration can increase the adsorption of phenol by activated carbon, but the increase in adsorption was less than $5 \%$ at higher phenol concentrations. The proposed mechanisms of the enhanced adsorption involve interactions between water-ion and adsorbate-ion in this system. Sodium chloride dissociates into $\mathrm{Na}^{+}$and $\mathrm{Cl}^{-}$in aqueous solution. There is a strong electrostatic field around the anions and cations, thus, an oriented array of water molecules is formed around these ions. The existence of ions enhances the combining powers between water-water molecules and strengthens the hydrophobicity of the adsorbate in the opposite direction (Pan et al., 2008; Mohamed 2011) which is beneficial for adsorption. In addition, the water solubility of the hydrophobic compound is reduced by an increase in ionic strength. This effect is known as 'salting-out' (Zhang et al., 2019). The strong influence of salts on the structure of water and water solubility of the adsorbate enhances phenol adsorption onto the surface of adsorbent. It was found that from the application of different models on the equilibrium data for phenol 
and PHBA, the data fitted well by the Frendluich isotherm model, instead of at high $\mathrm{NaCl}$ concentration in the case of PHBA, the experimental data was represented well by Langmuir model.

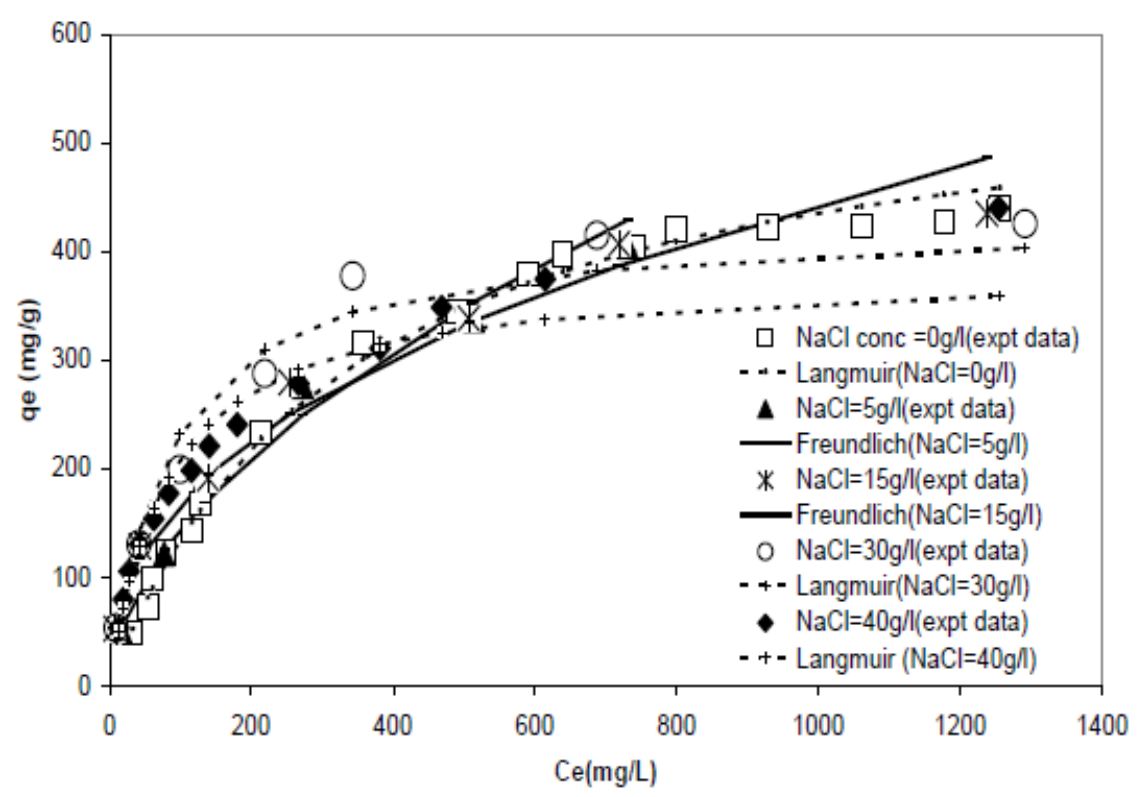

Figure 6. Effect of $\mathrm{NaCl}$ concentration on the adsorption of phenol onto AC S23 at temperature $25 \mathrm{C}^{\circ}$ and intial $\mathrm{pH}$ 6.3: Freundlich model fitting

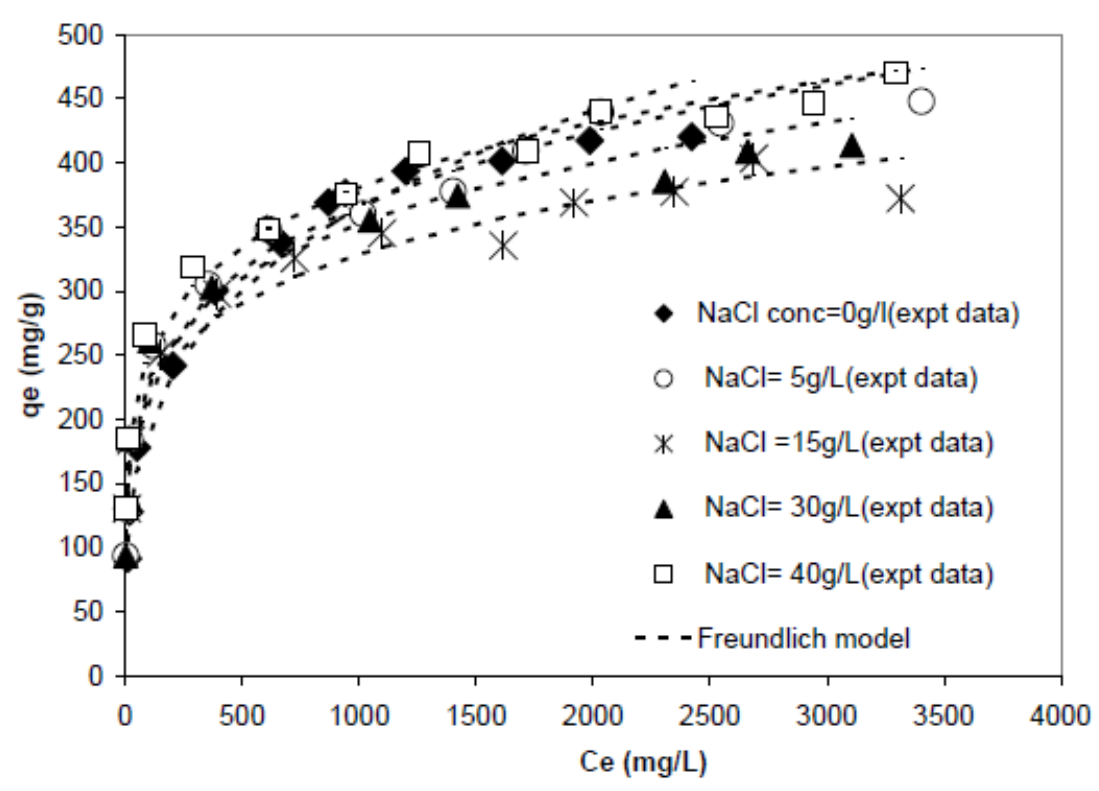

Figure 7. Effect of $\mathrm{NaCl}$ concentration on the adsorption of PHBA onto $\mathrm{S} 23$ at temperature $25 \mathrm{C}^{\circ}$ and intial $\mathrm{pH}$ 3.5: Freundlich model fitting for $\mathrm{NaCl} 5 \mathrm{~g} / \mathrm{l}$ and $15 \mathrm{~g} / \mathrm{L}$; Langmuir model fitting for $\mathrm{NaCl}$ concentration $30 \mathrm{~g} / \mathrm{l}$ and $40 \mathrm{~g} / \mathrm{l}$

\section{Conclusion}

The activated carbon S23 can be effectively used as adsorbent for the removal of organic 
compounds from industrial effluents and different aqueous solutions. The pseudo- first- order and pseudo- second- order kinetic models were used to analyse the data obtained for phenol and PHBA adsorption onto activated carbon S23. The results indicated that the pseudosecond- order equation provided the better correlation for the adsorption data. The solution $\mathrm{pH}$ played a significant effect in the organic compounds adsorption. Activated carbon adsorption capacity increased with the decreasing in the solution $\mathrm{pH}$. The adsorption is exothermic process decreased by increasing the temperature. The adsorption capacity of AC was slightly enhanced by an increase of salinity. This study is particularly important for the application of the adsorption process to saline industry wastewater treatment systems.

\section{References}

Al-Asheh, S., Banat, F., \& Masad, A. (2004). Kinetics and equilibrium sorption studies of 4nitrophenol on pyrolyzed and activated oil shale residue. Environmental Geology, 45, 1109-1117. https://doi.org/10.1007/s00254-004-0969-4

Altaher, H., Al-Ouf, F., Magdy, H., \& Hassan, M. (2015). Microwave against thermal treatment for manufacturing of activated carbon from agricultural wastes and its use to adsorb methylene blue- equilibrium and kinetic studies. Yanbu J Eng Sci., 11, 29-42.

Andriantsiferana, C., Mohamed, E., \& Delmas, H. (2015). Sequential adsorption photocatalytic oxidation process for wastewater treatment using a composite material $\mathrm{TiO}_{2} /$ activated carbon. Environ Eng Res., 20, 181-189. https://doi.org/10.4491/eer.2014.070

Banat, F., Al-sheh, S., \& Al-Makhadmeh, L. (2004). Utilization of raw and activated date pits for removal of phenol from aqueous solutions. Chem Eng Technol., 27, 80-86.

https://doi.org/10.1002/ceat.200401868

Bazrafshan, E., Amirian, P., Mahvi, H., \& Ansari-Moghaddam, A. (2016). Application of adsorption process for phenolic compounds removal from aqueous environments: a systematic review. Global NEST Journal, 18, 146-163. https://doi.org/10.30955/gnj.001709

Brucher, J., \& Bergstrom, L. (1997). Temperature dependence of linuron sorption to three different agricultural soils. J Environ Qual., 26, 1327-1335.

https://doi.org/10.2134/jeq1997.00472425002600050019x

Gu, H., Zhou, T., Zhang, L., \& Liu, F. (2008). Treatment of hyper-saline wastewater loaded with phenol by the combination of adsorption and an offline bio-regeneration system. Journal of Chemical Technology and Biotechnology, 83, 1034-1040. https://doi.org/10.1002/jctb.1910

Hameed, H., \& Rahman, A. (2008). Removal of phenol from aqueous solutions by adsorption onto activated carbon prepared from biomass material. Journal of Hazardous Materials, 160, 576-581. https://doi.org/10.1016/j.jhazmat.2008.03.028

Jaroniec, M. (1976). Statistical interpretation of the Jovanović adsorption isotherms. Colloid and Polymer Science, 254, 601-605. https://doi.org/10.1007/BF01382578

Joshi, J., Sahu, O. (2014). Minimization of Phenol by Natural Occurrence Adsorbent. International Letters of Natural Sciences, 11, 1-10. 
Li, J. M., Meng, X. G., Hu, C. W., \& Du, J. (2009). Adsorption of phenol, p-chlorophenol and p-nitrophenol onto functional chitosan. Bioresource Technology, 100(3), 1168-1173. https://doi.org/10.1016/j.biortech.2008.09.015

Machida, M., Goto, T., Amano, Y., \& Iida, T. (2016). Adsorptive Removal of Nitrate from Aqueous Solution Using Nitrogen Doped Activated Carbon. Chemical \& Pharmaceutical Bulletin, 64(11), 1555-1559. https://doi.org/10.1248/cpb.c16-00368

Magdy, M., Altaher, H., \& El Qada, E. (2018).Removal of three nitrophenols from aqueous solutions by adsorption onto char ash: equilibrium and kinetic modeling. Applied Water Science, 26, 2-15. https://doi.org/10.1007/s13201-018-0666-1

Mohamed, E. (2011). Removal of organic compounds from water by adsorption and photocatalytic oxidation. Thesis, University of Toulouse

Mohamed, E. F., El-Hashemy, M. A., Abdel-Latif, N. M., \& Shetaya, W. H. (2015). Production of sugarcane bagasse-based activated carbon for formaldehyde gas removal from potted plants exposure chamber. J Air Waste Manag Assoc., 65, 1413-1420.

https://doi.org/10.1080/10962247.2015.1100141

Mohamed, E. F., Awad, G., Andriantsiferana, C., \& El-Diwany, A. (2016a). Biofiltration technology for the removal of toluene from polluted air using Streptomyces griseus. Environ Technol., 37(10), 1197-1207. https://doi.org/10.1080/09593330.2015.1107623

Mohamed, E. F., Sayed. A. S. A., Abdel-Latif, N. M., \& Mekawy, A. (2016b). Air purifier devices based on adsorbents produced from valorization of different environmental hazardous materials for ammonia gas control. RSC Adv., 6, 57284-57292.

https://doi.org/10.1039/C6RA06630E

Mohammad, M. R., Afaj, A. H., \& Mahmoud, N. M. (2016). Study of some Effecting Factors on the Removal of Phenol from Aqueous Solutions by Adsorption onto Activated Carbon. $J$. Int. Environmental Application \& Science, 11(2), 148-153

Navarro, A. E., Portales, R. F., Sun-Kou, M. R., \& Llanos, B. P. (2008). Effect of pH on phenol biosorption by marine seaweeds. Journal of Hazardous Materials, 156, 405-411. https://doi.org/10.1016/j.jhazmat.2007.12.039

Pan, B., Pan, Bi, Zhang, W., Zhang, Q., Zhang, Q., \& Zheng, S. (2008). Adsorptive removal of phenol from aqueous phase by using a porous acrylic ester polymer. Journal of Hazardous Materials, 157(2-3), 293-299. https://doi.org/10.1016/j.jhazmat.2007.12.102

Sharma, P., Sohail, A. S., \& Tripathi, N. (2016) Isotherms describing physical adsorption of $\mathrm{Cr}(\mathrm{VI})$ from aqueous solution using various agricultural wastes as adsorbents. Cogent Engineering 3, 1186857, 1-20. https://doi.org/10.1080/23311916.2016.1186857

Srihari, V., \& Das, A. (2008). The kinetic and thermodynamic studies of phenol15 sorption onto three agro-based carbons. Desalination, 225(1-3), 220-234.

https://doi.org/10.1016/j.desal.2007.07.008 
Robati, D. (2013). Pseudo-second-order kinetic equations for modeling adsorption systems for removal of lead ions using multi-walled carbon nanotube. Journal of Nanostructure in Chemistry, 3(55), 2-6. https://doi.org/10.1186/2193-8865-3-55

Ullhyan, A., \& Ghosh, U. K. (2014). Removal of 2,4-dichlorophenol by simultaneous adsorption and biodegradation (SAB) using low cost adsorbent, Global NEST Journal, 16(4), 616-627. https://doi.org/10.30955/gnj.001260

Yang, W. B., Li, A. M., Zhang, Q. X., \& Fei, Z. H. (2005). Adsorption of 5-sodiosulfoisophthalic acids from aqueous solutions onto acrylic ester polymer YWB-7 resin. Sep. Purif. Technol., 46, 161-167. https://doi.org/10.1016/j.seppur.2005.05.005

Zhang, Y., Zhu, C., Liu, F., Yuan, Y., Wu, H., \& Li, A. (2019). Effects of ionic strength on removal of toxic pollutants from aqueous media with multifarious adsorbents: A review. Science of the Total Environment, 646, 265-279.

https://doi.org/10.1016/j.scitotenv.2018.07.279

\section{Copyright Disclaimer}

Copyright for this article is retained by the author(s), with first publication rights granted to the journal.

This is an open-access article distributed under the terms and conditions of the Creative Commons Attribution license (http://creativecommons.org/licenses/by/3.0/). 